\title{
Neurofibromatosis Type 1 in a Pediatric Population: Ste-Justine's Experience
}

\author{
J.M. Boulanger, A. Larbrisseau
}

\begin{abstract}
Background: To date, few pediatric series of neurofibromatosis type 1 (NF-1) have been described in the literature even though it is the most frequently encountered phakomatosis. Methods: We reviewed 987 charts of pediatric patients with a presumptive diagnosis of NF-1 who were evaluated at Ste-Justine hospital from January 1, 1991 to July 31, 2002. Patients who presented with two or more cardinal criteria were diagnosed with NF-1. Clinical and laboratory data were retrospectively collected, including: demographics, neuroimaging and presence or absence of associated symptoms or signs of NF-1. Results: A total of 279 patients were diagnosed with NF-1. The mean age at diagnosis was 3.4 years. Ninety-nine percent of the patients had café au lait spots and $47 \%$ had a first degree relative with NF-1. Almost 60 percent (59.6\%) of those seen by an ophthalmologist had Lisch nodules. Optic glioma was found in in $14.7 \%$, cutaneous neurofibromas in $38.4 \%$, plexiform neurofibromas in $24.7 \%$, neurofibrosarcoma in $1.8 \%$, learning disabilities in $39 \%$, attention deficit disorder in $40.5 \%$, osseous dysplasias in $7.2 \%$, pseudoarthrosis in $3.6 \%$, precocious puberty in $3.2 \%$ and short stature in $17.9 \%$. Magnetic resonance, when performed, showed hyperintense T2 lesions in $87.1 \%$ of cases. The mean period of follow-up was 7.4 years. Conclusion: Neurofibromatosis type 1 is a multisystemic disorder associated with increased risk of malignancy. It can be diagnosed at a very young age and clinical follow-up is advised. To our knowledge, this is the largest single center study of NF-1 in a pediatric population.
\end{abstract}

RÉSUMÉ: La neurofibromatose de type 1 dans une population pédiatrique : l'expérience de l'hôpital Ste-Justine. Introduction: Bien que la neurofibromatose de type 1 (NF-1) soit la phacomatose la plus fréquente, peu de séries de patients d'âge pédiatrique atteints de NF-1 ont été rapportées dans la littérature. Méthodes: Nous avons revu 987 dossiers de patients d'âge pédiatrique chez qui l'hypothèse retenue quant au diagnostic était la NF1, qui ont été examinés à l'hôpital Ste-Justine entre le 1er janvier 1991 et le 31 juillet 2002. Un diagnostic de NF-1 était posé si les patients présentaient deux critères cardinaux ou plus de la maladie. Les données cliniques et les résultats d'investigations suivants ont été colligés rétrospectivement: les informations démographiques, la neuroimagerie et la présence ou l'absence de symptômes ou de signes associés de la NF-1. Résultats: On a posé un diagnostic de NF-1 chez 279 patients. L'âge moyen des patients au moment du diagnostic était de 3,4 ans. Quatre-vingt-dix-neuf pour cent des patients avaient des taches café au lait et $47 \%$ avaient un apparenté au premier degré atteint de NF-1. À peu près soixante pour cent (59,6\%) de ceux qui ont été examinés par un ophtalmologiste avaient des nodules de Lisch. Un gliome optique était présent chez 14,7\%, des neurofibromes cutanés chez 38,4\%, des neurofibromes plexiformes chez $24,7 \%$, un neurofibrosarcome chez 1,8\%, des troubles d'apprentissage chez 39\%, un trouble de déficit de l'attention chez $40,5 \%$, des dysplasies osseuses chez 7,2\%, une pseudarthrose chez 3,6\%, une puberté précoce chez 3,2\% et une insuffisance staturale chez $17,9 \%$. Chez ceux qui ont subi une imagerie par résonance magnétique, on a observé des lésions hyper intenses en T2 chez $87,1 \%$ des cas. Le suivi moyen était de 7,4 ans. Conclusion: La neurofibromatose de type 1 est une maladie multisystémique associée à un risque accru de cancer. Le diagnostic peut être fait en très bas âge et un suivi s'impose. À notre connaissance il s'agit de la plus grande étude de patients pédiatriques atteints de NF-1 effectuée dans un même centre.

Can. J. Neurol. Sci. 2005; 32: 225-231

Neurofibromatosis type 1 (NF-1), or von Recklinghausen's disease is a common genetic disorder with an autosomal dominant mode of inheritance. ${ }^{1}$ The gene implicated is localised on chromosome 17 and codes for neurofibromin, a product partially homologus to guanosine-triphosphatase activating proteins. ${ }^{2,3}$ It is believed that neurofibromin acts as a tumor suppressor by down-regulating or inhibiting ras, a protooncogene. ${ }^{2,3}$

About half of cases of NF-1 are sporadic. ${ }^{4}$ Both genders are equally affected and the estimated incidence is 1 in 3000 live births. ${ }^{4}$ The diagnosis is often obvious from early childhood. ${ }^{5}$ Because genetic testing is not done on a routine basis and is expensive, the diagnosis is usually a clinical one; established by the criteria of the National Institutes of Health Consensus Development Conference Statement of $1988 .^{6}$

Neurofibromatosis type 1 is a multisystemic disease with a highly variable phenotype. Some patients have few or mild features while others have multiple complications. ${ }^{7}$ There is no

From the Division of Pediatric Neurology HSJ, Department of Pediatrics, Montreal University, Montreal, QC, Canada.

Received August 30, 2004. ACCEPTED In Final Form JanuARy 28, 2005.

Reprint requests to: Jean-Martin Boulanger, 1335, 12th Avenue S.W., Calgary, Alberta, Canada T3C $3 \mathrm{P} 7$ 
consensus or protocol for neuroimaging but clinical follow-up is advised. ${ }^{7}$

Most pediatric cases series were limited by the small number of patients, the inclusion of adults or the short duration of followup. We retrospectively studied pediatric patients with NF-1 who consulted at our center. The main purpose of this study is to further delineate the natural history of NF-1 in pediatric patients. In this article, we describe the clinical and laboratory data of these 279 patients.

\section{Methods}

\section{Patients selection and follow-up}

Pediatric patients with a presumptive diagnosis of NF-1 were evaluated at Ste-Justine hospital from January 1, 1991 to July 31, 2002. Patients were either seen at the neurofibromatosis outpatient clinic or during hospitalization. Charts were reviewed if a diagnosis of NF-1 (or possible NF-1) was mentioned on any consultation report or discharge summary or if the patients name was listed among those attending the neurofibromatosis clinic. Patients whose chart mentioned two or more diagnostic criteria (Appendix 1) were diagnosed with NF-1 according to the National Institutes of Health (NIH) Consensus Development Conference Statement of 1988. Duration of follow-up was defined as the time elapsed between the first evaluation date with a diagnosis of NF-1 until the last evaluation date.

In our center, patients followed at the neurofibromatosis clinic have regular clinical evaluations by a pediatric neurologist (every six to 12 months) and are seen by an ophthalmologist (annually or more frequently if needed). A complete neurological and systemic examination is performed. If needed, the patient is referred to a pediatric subspecialist. Magnetic resonance imaging (MRI) or computed tomography (CT) of the brain are performed if neurological, endocrinological or ophthalmological abnormalities are suspected. Neuroimaging may also serve as a diagnostic tool (for example: a patient with café au lait spots in which an asymptomatic optic glioma is found). Other radiological studies are done according to physician's judgment. The same protocol has been used from 1991 to 2002.

\section{Data collection and definitions}

Demographic data, including age at diagnosis, duration of follow-up and gender were recorded. Clinical and laboratory data that were collected include: family history, café au lait macules, freckling, neurofibromas, optic gliomas, Lisch nodules, typical osseous lesions (pseudoarthrosis and sphenoid/lambdoid dysplasias), neuroimaging findings (hyperintense T2 lesions, aneurysms, optic gliomas, aqueductal stenosis, Moya-Moya disease), scoliosis, macrocrania, developmental delay, learning disabilities, mental retardation, attention deficit disorder, high blood pressure, precocious puberty, seizures, neurofibrosarcomas and other type of tumors. Localization, evolution and treatment(s) of all tumors were reviewed. The treatment options were also noted for all NF-1 complications mentioned above. In patients with optic glioma, optic atrophy was diagnosed by a pediatric neuro-ophthalmologist.

Macrocrania was defined as a cranial perimeter above the 97th percentile and short stature as height below the tenth percentile for the patient's age. We defined a learning disorder as any situation where a school-aged child needed to be in a special class/school, failed a year-class, was in the lower rank of his class for more than one year or was diagnosed as such by the neuropsychologist. Mental retardation was defined as an intellectual quotient below 70. Developmental delay was subdivided in three categories: global delay, isolated speech delay and isolated motor delay. It was considered relevant for this study only if present on two subsequent neuropediatric evaluations. Attention deficit hyperactivity disorder (ADHD) was diagnosed according to DSM IV-R criteria. Neurofibromas were defined as plexiform if a biopsy confirmed the diagnosis or if the localization and shape of the neurofibroma were typical of it (e.g a neurofibroma implicating the face with ill defined borders). Finally, a patient was considered hypertensive if his blood pressure was over the 95th percentile for his age.

\section{Statistical analysis}

Categorical variables were compared using the Fisher exact probability test. Two-sided $\mathrm{p}$ values less than 0.05 were considered statistically significant. A Kaplan-Meier analysis was performed for survival probabilities calculation when some data were censored over time. Data were analysed with BioMeDical Package (BMDP) Statistical software.

\section{Results}

We reviewed the charts of 987 pediatric patients. Six hundred and sixty-three patients $(67.2 \%)$ had only one diagnostic criteria for NF-1 and never fulfilled the NIH criteria for a diagnosis of NF-1. A follow-up was possible in $92 \%$ (610) of these patients, with a mean duration of 5.7 years (0.5-12.3 years). Among patients with one cardinal feature of NF-1, 13 left the region, one died of a car accident, 34 missed their follow-up appointments and in 12 cases no reason was mentioned in the chart to justify the absence of subsequent visit. Fifteen patients had only optic glioma, four had a positive family history without other features of NF-1, one had only pseudoarthrosis and 643 patients had isolated café au lait spots.

Forty-five charts $(4.6 \%)$ had insufficient data to conclude about a diagnosis of NF-1. Therefore, 279 patients (28.3\%) were diagnosed with NF-1 according to NIH criteria and were included in our analysis. One hundred and forty-two subjects were males $(50.9 \%)$ and $137(49.1 \%)$ females. The mean age at diagnosis was 3.4 years (0-15.3 years) and the mean duration of follow-up was 7.4 years (0.5-14 years). About ten percent $(9.7 \%)$ of patients with a diagnosis of NF-1 were lost to follow-up: four patients left the city, 18 missed their follow-up appointments and no reason was mentioned in the chart in five cases.

One hundred and thirty-one (47\%) patients had a family history of NF-1 (Table 1). The disease was transmitted by the mother in $74(56.5 \%)$ cases and by the father in 57 cases $(43.5 \%)$.

A mean of three diagnostic criteria were present in each patient. Two hundred and thirty patients $(82.4 \%)$ were seen by an ophthalmologist. Among these, 137 (59.6\%) had Lisch nodules that were discovered at a mean age of 7.2 years (1.5-12 years). Café au lait spots were found in 277 patients (99.3\%) but freckling was mentioned in only 59 charts $(21.1 \%)$.

Optic glioma was found in 41 cases $(41 / 279 ; 14.7 \%)$ at a mean age of 5.1 years ( 0.6 year-11 years). Twelve patients with 
optic glioma $(12 / 41 ; 29.3 \%)$ had impairment of vision while optic atrophy was noted in 30 patients $(72.8 \%)$. Twenty cases $(48.8 \%)$ were bilateral, 26 cases affected the orbital nerves, 29 cases $(70.7 \%)$ involved the chiasm and 16 cases (39\%) extended to the retrochiasmatic region. Treatment was given to seven patients $(17.1 \%)$. Four patients received radiotherapy because of progression of visual impairment. All of them stabilized but none improved clinically. Neuroimaging showed moderate regression in two cases. Another patient had surgery because of rapidly progressive exophthalmos, blindness and optic atrophy. The pathology report confirmed a diagnosis of pilocytic astrocytoma of the optic nerve. No further therapy was needed in this case. Chemotherapy (carboplatin and vincristine) was used in another case of vision impairment and resulted in regression of the lesion of at least $50 \%$. One patient presenting with dysphagia, ataxia and torticollis had a brainstem glioma and a concomitant optic glioma. Radiotherapy was given with improvement of all symptoms. Unfortunately, the symptoms reappeared seven years later and despite chemotherapy (cisplatin and cyclophosphamide), the patient died. The autopsy revealed a gliomatosis cerebri, an optic nerve pilocytic astrocytoma and an anaplastic fibrillary astrocytoma of the brainstem. Eight cases $(19.5 \%)$ of optic glioma presented precocious puberty; all of these had a tumor involving the chiasm and/or the hypothalamus. A majority of optic gliomas (32 cases or 78\%) showed no radiologic progression. Overall, the mean duration of follow-up for the optic gliomas was 9.8 years (0.6-13 years).

Pseudoarthrosis was noted in ten patients $(3.6 \%)$ with a mean age at diagnosis of 2.9 years (0.3-3.5 years). Among four cases, only the tibia was involved. Five patients had both tibial and peroneal pseudoarthrosis. A pseudoarthrosis of the cubitus was found in one subject. Surgery was performed in six cases $(60 \%)$ while the mean number of procedures for those who required it was 4.3 operations per patient.

Sphenoid and lambdoid dysplasias were present in 17 ( $6.1 \%)$ and three $(1.1 \%)$ patients respectively. A majority of sphenoid dysplasias (13 cases or $76.5 \%$ ) were observed on the left side while bilateral lesions were quite rare (one case or $5.9 \%$ ). Seven cases $(41.2 \%)$ of sphenoid dysplasia were associated with exophthalmos.

One hundred and seven patients (38.4\%) exhibited two or more dermal/cutaneous neurofibromas. They first appeared at a mean age of 7.9 years (4-16 years) and none had malignant transformation. They varied in localization. The trunk was implicated in 58 cases $(54.2 \%)$, the neck in 49 cases $(45.8 \%)$, the head/face region in 41 cases $(38.3 \%)$ and upper limbs in 30 cases $(28 \%)$. Ten patients $(9.3 \%)$ had symptoms (mainly pain) and surgery or biopsy was performed in 17 cases $(15.9 \%)$. The mean time between diagnosis and excision of dermal/cutaneous neurofibromas was 3.6 years (0-8.5 years).

Ninety-six plexiform neurofibromas were observed in 69 patients $(24.7 \%)$ at a mean age of 5.8 years (3.5-14 years). A majority had surgery or biopsy (47 cases or $68.1 \%$ ) with a mean interval between apparition and surgery of 2.5 years (0.1-4.5 years). Total excision was possible in only $32 \%$ of operations. Progression was noticed in 66/96 (68.8\%) of plexiform neurofibromas but none had malignant transformation. Twenty four out of 30 cases $(80 \%)$ affecting the face were on the left side and $7 / 19$ cases $(36.8 \%)$ of eyelids plexiform neurofibromas were
Table 1: Neurofibromatosis type 1 (NF-1) diagnostic criteria in 279 pediatric patients

\begin{tabular}{lc}
\hline Diagnostic criteria & No. of cases $(\%)$ \\
Family history & $131(47)$ \\
Café au laits spots & $277(99.3)$ \\
Freckling & $59(21.1)$ \\
Dermal/cutaneous neurofibromas & $107(38.4)$ \\
Plexiform neurofibromas & $69(24.7)$ \\
Lisch nodules * & $137(49.1)$ \\
Osseous dysplasias & $20(7.2)$ \\
Optic gliomas & $41(14.7)$ \\
Pseudoarthrosis & $10(3.6)$
\end{tabular}

* $230(82.4 \%)$ patients were seen by an ophthalmologist

Table 2: Symptoms associated with plexiform neurofibromas in pediatric patients

\begin{tabular}{lc}
\hline Symptoms & No. of plexiform neurofibromas $(\boldsymbol{\%}) *$ \\
Ptosis & $14(14.6)$ \\
Amblyopia & $4(4.2)$ \\
Exophthalmos & $8(8.3)$ \\
Pain & $18(18.8)$ \\
Paresis & $4(4.2)$ \\
Paresthesias & $6(6.3)$ \\
Stroke & $1(1.0)$ \\
Torticollis & $1(1.0)$ \\
Abdominal obstruction & $1(1.0)$ \\
Asymptomatic & $54(56.2)$
\end{tabular}

* 96 plexiform neurofibromas were found, some causing more than one symptom

\# One patient had stroke following surgery for a cervical plexiform neurofibroma

associated with sphenoid dysplasia. Lower limbs (18 cases) and paravertebral (ten cases) plexiform neurofibromas were also frequent. Almost 44 percent $(43.8 \%)$ of plexiform neurofibromas were symptomatic (Table 2 ).

Neurofibrosarcomas were relatively rare (five cases or $1.8 \%$ ). None had prior diagnosed plexiform neurofibroma. The mean age at diagnosis was 10.3 years (3-14.5 years). Two cases had limb tumor while two patients had a paravertebral lesion. Triton tumor was found in the lower abdomen of a three-year-old child with urinary retention. Three patients with a neurofibrosarcoma received chemotherapy while radiotherapy was given to two patients. All cases had surgery and two had limb amputation. Three children reached adulthood but then were lost to followup. Despite treatments, one child died of his neurofibrosarcoma 3.5 years after the diagnosis.

A CT scan of the head was done in 250 patients $(89.6 \%)$ and MRI was performed in $93(33.3 \%)$ patients. Typical hyperintense $\mathrm{T} 2$ lesions were seen in 81 cases $(87.1 \%$ ) (Table 3$)$. They were 


\section{Table 3: Associated symptoms and signs of neurofibromatosis type 1 (NF-1) in 279 pediatric patients}

\begin{tabular}{lc}
\hline Symptoms/signs & No. of cases $(\%)$ \\
Scoliosis & $33(11.8)$ \\
Moya-Moya & $5(1.8)$ \\
Mental retardation & $17(6.1)$ \\
Learning disabilities* & $85(39)$ \\
Neurofibrosarcomas & $5(1.8)$ \\
Seizures & $9(3.2)$ \\
Attention deficit disorder & $113(40.5)$ \\
Hypertension & $4(1.4)$ \\
Developmental delay & $71(25.4)$ \\
Macrocrania & $53(19)$ \\
Precocious puberty & $9(3.2)$ \\
Short stature & $50(17.9)$ \\
Brain MRI T2 lesions & $81(87.1)$ \\
\end{tabular}

* 218 patients reached school age and were suitable for evaluation of learning disabilities

\# 93 patients had brain MRI

MRI = Magnetic resonance imaging

slightly more frequent among patients with an intracranial mass lesion than without $(92.9 \%$ vs $84.6 \%)$, although it did not reach statistical significance $(\mathrm{p}=0.23)$. These $\mathrm{T} 2$ lesions were observed in basal ganglia/thalamus (68 cases or $73.1 \%$ ), in the brainstem ( 53 cases or $57 \%$ ), in the cerebellum ( 47 cases or $50.5 \%$ ), in the subcortical white matter (ten cases or $10.8 \%$ ), in the hippocampus/parahippocampus region (six cases or 6.5\%) and in the corpus callosum (four cases or 4.3\%). Magnetic resonance imaging was abnormal in $97.1 \%$ of cases (34/35 patients) with learning disabilities and in $73 \%$ of cases (37/51 patients of school age and older) without it $(\mathrm{p}=0.002)$. Four patients with brain tumor were excluded from this analysis because their learning disabilities were judged to be related to their intracranial tumor (three cases with frontal glial tumors and one patient with gliomatosis cerebri).

Thirty-three patients had scoliosis (11.8\%). A majority of them were affected before puberty (29 cases or $87.9 \%$ ) but the overall prevalence of scoliosis increased with age (Table 3 ). The mean age at diagnosis was 11.8 years (3.5-16 years). Ten cases $(30.3 \%)$ necessitated surgery and six patients $(18.2 \%)$ had underlying neurofibromas.

Macrocrania was noted in 53 patients (19\%). One hundred and thirteen children (40.5\%) presented with ADHD; most of whom had only attention deficit (73 cases or $64.6 \%$ ) without hyperactivity. Ninety-one $(80.5 \%)$ of them needed psychostimulant medication.

Learning disabilities were present in 85 out of 218 (39\%) school-aged children and in 54\% of patients with ADHD. Developmental delay was observed in 71 patients $(25.4 \%)$ and consisted mostly of global delay (43/71 cases or $60.6 \%)$. Isolated language delay was found in 20/71 children (28.2\%) and isolated motor delay in $8 / 71$ patients $(11.3 \%)$. Seventeen cases $(6.1 \%)$ of mental retardation were reported. Formal neuropsychological assessment was obtained in 94 patients $(33.7 \%)$.

Five patients had Moya-Moya disease $(1.8 \%)$ at a mean age of 8.9 years (4-12.3 years). Two of them had received prior brain radiotherapy. Four patients $(80 \%)$ developed focal symptoms (hemiparesis, aphasia or focal seizures) and one patient died of gliomatosis cerebri (case mentioned above). Magnetic resonance imaging revealed ischemic lesions in all cases. No cerebral hemorrhage was found. Despite treatment with aspirin and calcium antagonists, all showed progression of their ischemic lesions on neuroimaging.

Only nine children had seizures (3.2\%). Three of them had underlying cerebral pathology (ischemic lesion secondary to Moya-Moya, gliomatosis cerebri and arteriovenous malformation). Hypsarrythmia and infantile spasms were observed in a child with severe mental retardation. This patient did not develop subsequent epilepsy.

High blood pressure was present in only four cases $(1.4 \%)$. All cases were associated with bilateral renal artery stenosis. It was first noticed at a mean age of 4.5 years (4-6 years). One patient had a symptomatic mesencephalic hemorrhage as a complication of his hypertension.

Precocious puberty was found in nine patients (3.2\%). It was strongly associated with optic glioma with chiasmatic/ hypothalamic extension (seven cases or 78\%). One patient with an optic glioma was treated with radiotherapy prior to the development of his precocious puberty. Fifty patients $(17.9 \%)$ had short stature.

Four patients $(1.4 \%)$ had aqueductal stenosis that required shunting. Five children (1.8\%) had dural ectasies and meningoceles. Two suspected radiological cases of cerebral glioma and one proven case of frontal ganglioglioma were found. The latter had surgery and is stable 1.5 years after his operation. No further therapy was instituted. Adrenal neuroblastoma was discovered in a four-month-old girl. Surgery was performed and the patient remains tumor free four years later.

Finally, no cerebral aneurysm or pheochromocytoma has been found.

\section{Discussion}

In this study, we present a cohort of 279 pediatric patients with NF-1. The mean duration of follow-up was 7.4 years and the mean age at diagnosis was 3.4 years. Many children were already three to four years old when first referred to our center for diagnosis. Yet, NF-1 can often be easily recognized by expert clinicians at a very young age. About 20\% (56 patients) of our cases were diagnosed before two years of age.

A majority of patients initially evaluated (663 patients; $67.2 \%$ ) had only one diagnostic criteria and did not subsequently develop NF-1.

To our knowledge, this is the largest single center case series of neurofibromatosis type 1 in a pediatric population. Being retrospective, this study has some limitations. For example, we certainly underestimated the prevalence of freckling. When two or more diagnostic criteria were already present, freckling was often overlooked (because of the lack of clinical consequence) or not mentioned in the chart by the principal pediatric neurologist. 
Table 4: Prevalence of NF-1 complications according to age*

\begin{tabular}{lccc}
\hline $\begin{array}{l}\text { NF-1 associated } \\
\text { Signs }\end{array}$ & $\begin{array}{c}\leq \mathbf{5} \text { years old } \\
(\mathbf{n = 2 3 1})\end{array}$ & $\begin{array}{c}\mathbf{5} \text { to 10 years } \\
(\mathbf{n = 2 2 0})\end{array}$ & $\begin{array}{c}>10 \text { years } \\
(\mathbf{n}=\mathbf{7 9})\end{array}$ \\
& $\mathbf{n}(\boldsymbol{\%})$ & $\mathbf{n}(\boldsymbol{\%})$ & $\mathbf{n}(\mathbf{\%})$ \\
Café au lait spots & $229(99.1)$ & $219(99.5)$ & $79(100)$ \\
$\begin{array}{l}\text { Lisch nodules } \\
\text { Cutaneous }\end{array}$ & $81(35.1)$ & $131(59.5)$ & $65(82.3)$ \\
$\quad$ neurofibromas & $23(10)$ & $81(36.8)$ & $46(58.2)$ \\
$\begin{array}{l}\text { Plexiform } \\
\quad \text { neurofibromas }\end{array}$ & $44(19)$ & $64(29.1)$ & $20(25.3)$ \\
$\begin{array}{l}\text { Optic gliomas } \\
\text { Scoliosis }\end{array}$ & $33(14.3)$ & $38(17.3)$ & $19(24.1)$ \\
Brain tumors & $11(4.8)$ & $28(12.7)$ & $12(15.2)$ \\
Neurofibrosarcomas & $0(0)$ & $1(0.005)$ & $3(3.8)$ \\
& $1(0.004)$ & $1(0.005)$ & $3(3.8)$
\end{tabular}

* The mean follow-up was 7.4 years. Therefore, the same patients are present in different age groups.

Nevertheless, other clinical complications and features of NF-1 were carefully evaluated. Furthermore, the prevalence of most diagnostic criteria in our study is similar to what was previously reported (Table 5), ${ }^{4,7,9}$ Huson et $\mathrm{al}^{4}$ found a higher rate of plexiform neurofibromas ( $43.6 \%$ vs $24.7 \%$ in our review) but the number (39) of pediatric patients evaluated in their cohort was relatively small. Obringer et $\mathrm{al}^{9}$ had few patients with Lisch nodules $(28 \%)$ but their patients were six years old or younger. For patients younger than five years old, we also found a lower rate $(35.1 \%)$ of Lisch nodules than in patients over ten years old $(82.3 \%)$ (Table 4).

About one sixth of the patients in our cohort had an optic nerve glioma. In previous studies, the prevalence of optic nerve glioma in NF-1 has been estimated from $4 \%$ to $19 \%$; being lower if only symptomatic patients were screened and higher if routine neuroimaging was done., ${ }^{4-10}$ Visual impairment was found in $29.3 \%$ of our patients but optic atrophy was more common $(72.8 \%)$. It is known that aggressive tumor behavior and symptoms are more frequent among sporadic optic gliomas than those related to $\mathrm{NF}-1 .^{11}$ In the literature, retrochiasmatic extension is sometimes associated with an unfavorable prognosis. ${ }^{12}$ However, despite a high prevalence of retrochiasmatic extension (39\% of cases), we could not find such association in the present study. The overall behavior of optic gliomas is rarely aggressive and most tumors do not show radiological $(73.9 \%$ at 11 years; Figure 1$)$ or clinical $(81.8 \%$ at 11 years; Figure 2) progression even after many years of followup. In our cohort, only a minority $(17.1 \%)$ of patients required treatment. Indeed, there is a consensus that treatment should be limited for patients with progressive ophthalmological symptoms. ${ }^{13}$ Spontaneous regression of optic gliomas, even when symptomatic, has been described. ${ }^{14}$ As such, we should refrain from treating them too aggressively. Furthermore, precocious puberty in the present study seemed to be strongly, but not exclusively, associated with chiasmatic/hypothalamic gliomas. This is concordant with previous literature. ${ }^{15,16}$

Neurofibrosarcomas were rare $(1.8 \%)$. No plexiform neurofibroma evolved to a neurofibrosarcoma. This may indicate
Table 5: Comparison between different cohorts of children with neurofibromatosis type 1 (NF-1)

\begin{tabular}{|c|c|c|c|c|}
\hline $\begin{array}{l}\text { NF-1 associated } \\
\text { features }\end{array}$ & $\begin{array}{c}\text { Present } \\
\text { study } \\
(\%)\end{array}$ & $\begin{array}{c}\text { Cnossen \& } \\
\text { Colleagues }^{7} \\
(\%)\end{array}$ & $\begin{array}{c}\text { Huson \& } \\
\text { Colleagues }^{4} \\
(\%)^{\#}\end{array}$ & $\begin{array}{c}\text { Obringer \& } \\
\text { Colleagues }^{9} \\
\quad(\%)\end{array}$ \\
\hline Café au lait spots & $277(99.3)$ & 145 (96.7) & $98.2 \%$ & 109 (97) \\
\hline $\begin{array}{l}\text { Freckling } \\
\text { Cutaneous }\end{array}$ & $59(21.1)$ & $128(85.3)$ & $70 \%$ & $91(81)$ \\
\hline $\begin{array}{l}\text { Neurofibromas } \\
\text { Plexiform }\end{array}$ & $107(38.4)$ & $60(40)$ & $39.2 \%$ & $17(15)$ \\
\hline Neurofibromas & 69 (24.7) & $40(26.6)$ & $43.6 \%$ & - \\
\hline $\begin{array}{l}\text { Neurofibro- } \\
\text { sarcomas }\end{array}$ & $5(1.8)$ & $3(2)$ & $0 \%$ & - \\
\hline Lisch nodules & $137(49.1)$ & $78(52)$ & $83.9 \%$ & $34(28)$ \\
\hline Optic glioma & $41(14.7)$ & $17(11.3)$ & $5.1 \%$ & $5(4)$ \\
\hline $\begin{array}{c}\text { Sphenoid/lambdoi } \\
\text { dysplasia }\end{array}$ & d $20(7.2)$ & $11(7.8)$ & - & $7(6)$ \\
\hline $\begin{array}{l}\text { Mental } \\
\quad \text { retardation }\end{array}$ & $17(6.1)$ & $19(17.2)$ & - & - \\
\hline Seizures & $9(3.2)$ & $1(0.7)$ & $5.1 \%$ & - \\
\hline $\begin{array}{l}\text { Pseudoarthrosis } \\
\text { Aqueduct }\end{array}$ & $10(3.6)$ & $3(2)$ & $5.1 \%$ & - \\
\hline stenosis & $4(1.4)$ & $1(0.7)$ & $0 \%$ & - \\
\hline $\begin{array}{l}\text { Precocious } \\
\text { puberty }\end{array}$ & $9(3.2)$ & $3(2)$ & - & - \\
\hline Scoliosis & $33(11.8)$ & $3(2)$ & $5.1 \%$ & - \\
\hline Brain tumor* & $4(1.4)$ & $4(2.7)$ & - & - \\
\hline Total $(\%)$ & $279(100)$ & $150(100)$ & $(100)$ & $112(100)$ \\
\hline
\end{tabular}

* Optic glioma are not included

\# Absolute numbers of patients are not stated since the patients ascertained in this study varied according to the NF-1 feature evaluated. Furthermore, some numbers were not mentioned by the authors.

a low malignancy transformation rate among plexiform neurofibromas or be partly due to an age-related phenomenon. A very rapid growth should raise the suspicion of malignant transformation. However, many plexiform neurofibromas showed an increase in size $(68.8 \%)$ or were symptomatic $(46.4 \%)$. A total excision could be accomplished in only $32 \%$ of surgeries. Therefore, although pathologically benign, many of these neurofibromas are troublesome for patients. Tumors of the head, neck and face are often of particular concern. ${ }^{17}$ Biological markers, like immunohistochemical detection of p53, might be helpful to predict tumors that are likely to progress to malignancy. ${ }^{18}$ In our center, $80 \%$ of facial plexiform neurofibromas and $76.5 \%$ of sphenoid dysplasias were on the left side. Such findings are not reported in the literature. Furthermore, sphenoid dysplasia was associated with eyelid plexiform neurofibromas in $36.8 \%$ of cases while it was present in only $3.8 \%$ of patients without eyelid plexiform neurofibroma.

We also had a great number of patients with attention deficit disorder (40.5\%). The association between NF-1 and ADHD was already known but not well-characterized. ${ }^{19}$ The high prevalence of ADHD in NF-1 is probably part of the behavioral phenotype 


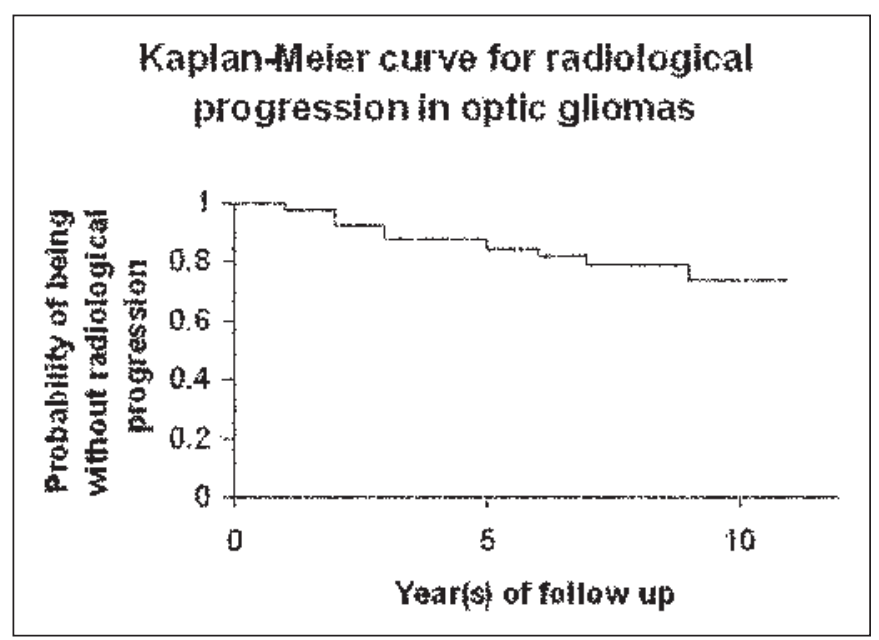

Figure 1: Probability for pediatric patients with NF-1 and optic gliomas of being without radiological progression according to duration of follow-up

sometimes seen in NF-1 that includes learning disabilities $(39 \%)$ and, more rarely, mental retardation $(6.1 \%)$. Only $33.7 \%$ of our patients had formal neuropsychological assessment. It is therefore possible that subtle cases of learning disabilities were missed. Nevertheless, this seems unlikely in cases with mental retardation.

Animal models give us insight in the pathophysiology of learning deficits in NF-1. It is possible that increased Ras GTPase activity mediates deficits in long-term potentiation and promotes gamma-aminobutyric acid (GABA) inhibition. ${ }^{20}$ In the brain, neurofibromin has also been shown to bind cytoplasmic microtubules and might be involved in signal pathways. ${ }^{21}$ Although some data suggest ${ }^{22,23}$ a relationship between MRI unidentified bright objects and learning impairment, this has not been consistently demonstrated. ${ }^{24-27}$ In the present study, we found a higher incidence of unidentified bright objects in patients with learning disorder $(97.1 \%)$ compared to the other children $(73.1 \%)(\mathrm{p}=0.002)$. However, a retrospective study like this one is subject to the usual biases of ascertainment and premature conclusions should be withheld until a large prospective study is done.

We had a relatively low number of patients (1.4\%) with hypertension compared to some studies which had rates as high as $18.5 \%{ }^{28,29}$ We did not use ambulatory blood pressure monitoring, which is known for being more sensitive than sporadic blood pressure measurements. ${ }^{28}$ Therefore, it is possible that we underestimated the prevalence of hypertension in our population. Hypertension was a consequence of renal artery stenosis in all of our cases.

We also found an increase in seizure prevalence $(3.2 \%)$ compared to what is expected in the general population. This is similar to previous data. ${ }^{30} \mathrm{~A}$ third of our patients with seizures had underlying cerebral lesion. Brain imaging should be done in pediatric patients with NF-1 and seizures. Nevertheless, it remains a rare complication of NF-1.

In conclusion, NF-1 is a multisystemic disease with a high frequency of learning disorders and increased incidence of

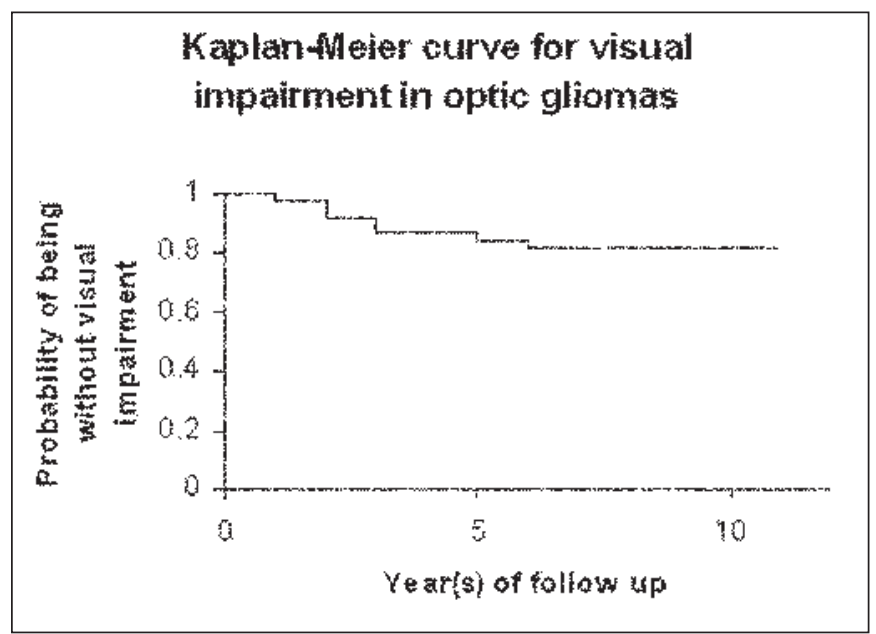

Figure 2: Probability for pediatric patients with NF-1 and optic gliomas of being without visual impairment according to duration of follow-up

malignancy. Therefore, and because many complications of NF1 increase in frequency with age (Table 4), a long term clinical follow-up is advised. We propose to do annual neurological and ophthalmological evaluations in children with NF-1. If the patients are symptomatic (e.g visual impairment and presence of an optic glioma), they should be evaluated more frequently. We believe that NF-1 can be diagnosed early in children. The NIH criteria are also adequate for the pediatric population. There is no consensus about the neuroradiological screening and follow up in asymptomatic patients. We believe that MRI is a useful adjunct to clinical evaluation in the diagnosis of equivocal cases. ${ }^{31}$ However, we do not suggest that an MRI should be done on a screening basis for obvious NF-1 cases that are neurologically asymptomatic.

\section{ACKNOWLEDGEMENTS}

The authors received no financial funding.

\section{REFERENCES}

1. Barker D, Wright E, Nguyen K, et al. Gene for von Recklinghausen neurofibromatosis is in the pericentromeric region of chromosome 17. Science 1987;236:1100-1102.

2. Weiss B, Bollag G, Shannon K. Hyperactive Ras as a therapeutic target in neurofibromatosis type. AM J Med Genet 1999;89:1422.

3. Martin GA, Viskochil D, Bollag G, et al. The GAP-related domain of the neurofibromatosis type 1 gene product interacts with ras p21. Cell 1990;63:843-849.

4. Huson SM, Compston DA, Harper PS. A genetic study of von Recklinghausen neurofibromatosis in south east Wales. II. Guidelines for genetic counselling. J Med Genet 1989;26:712729.

5. DeBella K, Szudek J, Friedman JM. Use of the national institutes of health criteria for diagnosis of neurofibromatosis 1 in children. Pediatrics 2000;105:608-614.

6. National Institutes of Health Consensus Development Conference Statement: neurofibromatosis; Bethesda, Md., USA, July 13-15, 1987. Neurofibromatosis 1988;1:172-178.

7. Cnossen MH, de Goede-Bolder A, van den Broek KM, et al. A 
prospective 10 year follow-up study of patients with neurofibromatosis type 1. Arch Dis Child 1998;78:408-412.

8. Huson SM, Neurofibromatosis 1: a clinical and genetic overview. Hughes RAC (Eds). The Neurofibromatoses: A Pathogenetic and Clinical Overview. London: Chapman and Hall, 1994; 160-203

9. Obringer AC, Meadows AT, Zackai EH. The diagnosis of neurofibromatosis-1 in the child under the age of 6 years. Am J Dis Child 1989;143:717-719.

10. Listernick R, Charrow J, Greenwald M, Mets M. Natural history of optic pathway tumors in children with neurofibromatosis type 1: a longitudinal study. J Pediatr 1994;125:63-66.

11. Singhal S, Birch JM, Kerr B, Lashford L, Evans DG. Neurofibromatosis type 1 and sporadic gliomas. Arch Dis Child 2002;87:65-70.

12. Balcer LJ, Liu GT, Heller G, et al. Visual loss in children with neurofibromatosis type 1 and optic pathway gliomas: relation to tumor location by magnetic resonance imaging. Am J Ophthalmol 2001;131:442-445.

13. Mikaeloff Y, Chaix Y, Grill J, et al. Optic pathway gliomas in neurofibromatosis type 1 . Longitudinal study of 30 cases in two multidisciplinary practices (French). Arch Pediatr 2002;9;797804.

14. Parsa CF, Hoyt CS, Lesser RL, et al. Spontaneous regression of optic gliomas: thirteen cases documented by serial neuroimaging. Arch Ophthalmol 2001;119:516-529.

15. Cnossen MH, Stam EN, Cooiman LC, et al. Endocrinologic disorders and optic pathway gliomas in children with neurofibromatosis type 1. Pediatrics 1997;100:667-670.

16. Virdis R, Sigorini M, Laiolo A, et al. Neurofibromatosis type 1 and precocious puberty. J Pediatr Endocrinol Metabol 2000;13 (Suppl 1):841-844

17. Needle MN, Cnaan A, Dattilo J, et al. Prognostic signs in the surgical management of plexiform neurofibromas: the Children's Hospital of Philadelphia experience. J Pediatr 1997;131:678-682.

18. McCarron KF, Goldblum JR. Plexiform neurofibroma with and without associated malignant peripheral nerve sheath tumor: a clinicopathologic and immunohistochemical analysis of 54 cases. Mod Pathol 1998;11:612-617.

19. Koth CM, Cutting LE, Denckla MB. The association of neurofibromatosis type 1 and attention deficit hyperactivity disorder. Child Neuropsychol 2000;6:185-194.

20. Costa RM, Federov NB, Kogan JH, et al. Mechanism for the learning deficits in a mouse model of neurofibromatosis type 1 . Nature 2002;415:526-530.

21. Gutmann D. Recent insights into neurofibromatosis type 1: Clear genetic progress. Arch of Neurol 1998;55:778-780.

22. North K, Joy P, Yuille D, et al. Specific learning disability in children with neurofibromatosis type 1: significance of MRI abnormalities. Neurology 1994;44:878-883.

23. Feldmann R, Denecke J, Grenzebach M, Schuierer G, Meglage J. Neurofibromatosis type 1: motor and cognitive function and T2weighted MRI hyperintensities. Neurology 2003; 61:1725-1728.
24. Hyman SL, Gill DS, Shores EA, et al. Natural history of cognitive deficits and their relationship to MRI T2-hyperintensitis in NF-1. Neurology 2003;60:139-145.

25. Legius E, Descheemaeker MJ, Steyaert J, et al. Neurofibromatosis type 1 in childhood: correlation of MRI findings with intelligence. J Neurol Neurosurg Psychiatry 1995;59:638-640.

26. Moore BD, Slopis JM, Schomer D, Jackson EF, Levy BM. Neuropsychological significance of areas of high signal intensity on brain MRIs of children with neurofibromatosis. Neurology 1996; 46:1660-1668.

27. North KN, Riccardi V, Samango-Sprouse C, et al. Cognitive function and academic performance in neurofibromatosis type 1: consensus statement from the NF-1 Cognitive Task Force. Neurology 1997;48:1121-1127.

28. Fossali E, Signori E, Intermite RC, et al. Renovascular disease and hypertension in children with neurofibromatosis. Pediatr Nephrol 2000; 14:806-810.

29. Virdis R, Balestrazzi P, Zampolli M, et al. Hypertension in children with neurofibromatosis. J Hum Hypertens 1994;8:395-397.

30. Kulkantrakorn K, Geller TJ. Seizures in neurofibromatosis 1 . Pediatr Neurol 1998;19;347-350.

31. Es SV, North KN, McHugh K, Silva MD. MRI findings in children with neurofibromatosis type 1: a prospective study. Pediatr Radiol 1996; 26:478-487.

\section{APPENDIX}

National Institutes of Health (NIH) diagnostic criteria for neurofibromatosis type 1 NF-1 (Consensus Development Conference of 1988)

At least two of the following:

A. Six or more café au lait macules over $5 \mathrm{~mm}$ in greatest diameter in prepubertal individuals and over $15 \mathrm{~mm}$ in greatest diameter in postpubertal individuals

B. Two or more neurofibromas of any type or one or more plexiform neurofibroma(s)

C. Freckling in the axillary or inguinal regions

D. Optic or chiasma glioma

E. Two or more Lisch nodules (iris hamartomas)

F. A distinctive osseous lesion such as sphenoid dysplasia or thinning of long bone cortex, with or without pseudoarthrosis

G. A first degree relative with NF-1 by the above criteria 